\title{
EL ÁMBITO DE LA CONSTITUCIÓN*
}

\author{
Francisco J. Laporta \\ Universidad Autónoma de Madrid
}

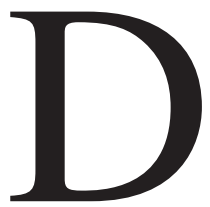

esde hace algunos años vengo insistiendo en que es necesario volver a reivindicar con fuerza el papel de las leyes en la composición del sistema jurídico, tanto por razones de naturaleza prudencial como por razones de naturaleza moral. He sugerido incluso que hay que proceder a una suerte de reinvención de la ley como fuente del derecho para hacer frente a todos los graves fenómenos que se vienen denunciando bajo la fórmula genérica de «crisis de la ley». Sería estúpido minimizar o ignorar todos esos problemas de degradación de la legislación que se señalan desde hace ya tiempo, pero tengo la convicción de que hay que hacerles frente con la vista puesta en el perfeccionamiento del contenido, el alcance y los procedimientos de elaboración de la ley misma, mucho más que recurriendo a otros mecanismos del sistema institucional, como el fomento del activismo judicial, o acudiendo a otros ingredientes del ordenamiento, como la invocación de la Constitución en todo litigio imaginable o de los principios del derecho y esa su presunta naturaleza «pregnante» de todo el orden jurídico.

Lo que afirmo es que no es bueno olvidar una cosa que nos ha parecido obvia durante mucho tiempo: que para conseguir una articulación satisfactoria de la sociedad como un «sistema justo (fair) de cooperación» (Rawls, 2001) es necesario que el componente principal del ordenamiento sea un cuerpo firme de leyes entendidas como vehículos normativos coherentes de reglas generales y abstractas, razonablemente estables, y a las que todos, profesionales liberales, jueces y funcionarios, deban una especial y acentuada deferencia en el momento de la aplicación del derecho. Esas leyes tienen que ser el alma del funcionamiento de la máquina jurídica en nuestras sociedades. Cosas tales como la definición de la condición ciudadana, la or-

\footnotetext{
* Este trabajo es una reelaboración, a veces profunda, de la lección que pronuncié el día 24 de enero de 2002 en un curso de doctorado de la Universidad Castilla-La Mancha (Toledo) a invitación de mis colegas Juan Ramón de Páramo y Luis Prieto. Aprovecho esta oportunidad para expresarles mi gratitud.
} 
ganización de la familia, el funcionamiento de la Administración y las agencias gubernativas, los criterios y pautas de adscripción de derechos de propiedad y de distribución de las cargas y beneficios de la cooperación social, las coordenadas básicas del sistema económico, las condiciones del tráfico de bienes y servicios, la protección y límites de los derechos y libertades básicas, las pautas de organización del uso de la fuerza en la sociedad, el alcance y competencia de los distintos poderes, la disciplina procesal de los tribunales y tantas otras cosas, tienen que ser establecidas mediante leyes generales, públicas y claras, no retroactivas y coherentes entre sí1.

Lo que sucede es que la propuesta de acentuar el protagonismo de la ley en el ordenamiento tiene que acabar por suscitar algunas incógnitas sobre el fundamento y el alcance de la Constitución. Y ello porque las relaciones recíprocas entre ley y Constitución podrían ser descritas adecuadamente mediante la metáfora del flujo y reflujo de las mareas, de forma tal que el avance de la ley implique el retroceso de la Constitución, y el incremento del protagonismo de la Constitución suponga de algún modo la bajamar de la ${ }^{l e y^{2}}$. Creo poder afirmar que estamos en un momento en el que la Constitución, las constituciones, animadas por un sector de la teoría, han conquistado un territorio demasiado extenso, y ello debe ser sometido a examen crítico $^{3}$. Lo que me propongo hacer, en consecuencia, es cuestionar los límites de contenido y alcance de la Constitución, el lugar de la Constitución en el ordenamiento. $\mathrm{O}$, si prefieren expresarlo de otra manera, reflexionar sobre el núcleo esencial de la Constitución, los constitutional essentials (Rawls 2001, 28).

Esto es algo que no han hecho en general nuestros constitucionalistas, pues han estado -me parece- situados muy decididamente en el «punto de vista interno», dando por hecho -seguramente con razón- que su misión no era cuestionar sino conocer, sistematizar y en su caso aplicar la Constitución. Sin embargo sí lo han hecho con particular sagacidad algunos filósofos del derecho españoles ${ }^{4}$ a los que voy a seguir aquí en bastantes extremos.

\section{I}

¿Cuál es el problema que tendríamos, pues, que abordar? Se trata de un problema que está en el centro de la concepción política y ética que se vie-

\footnotetext{
${ }^{1}$ En este sentido no creo que debamos aceptar que estamos en la «edad de la descodificación», sino que propugno más bien que iniciemos con seriedad una nueva codificación

${ }^{2}$ La metáfora del flujo de las mareas fue utilizada en el mismo sentido por Víctor Pérez Díaz para describir las cambiantes relaciones entre Estado y sociedad civil.

${ }^{3}$ Por todos, Zagrebelsky (1992, 21 y ss.) Para una excelente introducción a este proceso, véase Pozzolo (2001, capítulo I)

${ }^{4}$ Véase en particular, José Juan Moreso, La Indeterminación del Derecho y la interpretación de la Constitución. Madrid. Centro de Estudios Constitucionales. 1997; Luis Prieto Sanchís, Constitucionalismo y Positivismo. México. Fontamara. 1997, y «Tribunal Constitucional
} 
ne denominando «constitucionalismo», pero me apresuro a advertir que esa concepción incluye al menos dos grandes ideas-fuerza que es preciso diferenciar $^{5}$. La primera tiene que ver con la estructura jerarquizada del ordenamiento, y es la exigencia de que por encima de las leyes emanadas del poder legislativo se sitúe un texto jurídico que tengan primacía sobre ellas, es decir, que sea jerárquicamente superior a las leyes, y al que se llama comúnmente Constitución. La segunda, que es diferenciable de la anterior y no se deriva necesariamente de ella ${ }^{6}$, es la idea que postula que esa primacía de la Constitución sobre la ley ha de garantizarse recurriendo a procedimientos judiciales y debe llevarse a cabo por órganos del poder judicial, es decir, se sitúa más bien en el terreno del procedimiento de adjudicación. En las dos puede darse una «objeción democrática», o una formulación propia de la objeción democrática, y por ello es conveniente distinguirlas. En este trabajo voy a ocuparme solo de la primera, presuponiendo que las conclusiones que alcancemos sobre ella no condicionan necesariamente la respuesta que pueda darse a la segunda cuestión, aunque puedan arrojar alguna luz sobre ella.

Para lo que aquí interesa la primera objeción o la primera forma de la objeción democrática pudiera formularse así: supuesto que exista un órgano legislativo que represente fidedignamente ${ }^{7}$ a la mayoría de los ciudadanos y su pluralidad de convicciones, opiniones y preferencias, y que tome sus decisiones mediante la regla de la mayoría ¿cuál puede ser la razón que justifique la existencia de un texto constitucional que se superponga a ese órgano y limite sus competencias legislativas dificultando o excluyendo de sus deliberaciones y decisiones determinadas materias? Porque hay quien ha recordado que la noción de «democracia constitucional» ha podido ser considerada un oxímoron (Cfr. Holmes 1988) ya que, si un sistema político es democrático entonces no admite la limitación constitucional, y si es constitucional no admite la decisión democrática sobre algunas materias importantes. En efecto, desde esta perspectiva, casi todas las Constituciones

\footnotetext{
y Positivismo», en Doxa, 23, 2000. Es imprescindible el intercambio de puntos de vista entre José Juan Moreso ,"Derechos y Justicia Procesal Imperfecta», y Juan Carlos Bayón, «Derechos, Democracia y Constitución», en Derechos y Justicia Constitucional en Discusiones, año $\mathrm{I}^{\mathrm{o}} 1$, en quienes me inspiro en buena parte de este trabajo. Como excepción relevante entre nuestros constitucionalistas, Víctor Ferreres Comella, Justicia Constitucional y Democracia. Madrid. Centro de Estudios Constitucionales. 1997.

${ }^{5}$ Para un elenco de los distintos significados de «Constitucionalismo» (Pozzolo 2001).

${ }^{6}$ La aparente fuerza de la argumentación de Marshall en Marbury v. Madison ha determinado que muchos mantengan que el control judicial se sigue necesariamente de la supremacía de la Constitución, pero la fuerza de ese argumento es solo aparente (Cfr. Nino 1993)

${ }^{7}$ Quiero subrayar que no estoy tratando aquí de ninguna situación de hecho o de derecho de ningún país, sino de un problema teórico que creo importante. Qué sea una representación satisfactoria desde este punto de vista es algo que tendríamos que empezar a pensar a partir de aquí, no es algo ya dado de antemano en ninguna ley vigente.
} 
actuales suelen tener al menos dos rasgos característicos: son en primer lugar vehículo de normas que acuerdan ciertas limitaciones a la agenda de los poderes legislativos ${ }^{8}$, y son en segundo lugar documentos dotados de una grado mayor o menor de rigidez. En virtud de estos dos rasgos necesariamente se superponen a los órganos legislativos sin que éstos puedan incluir sin dificultad en sus deliberaciones y decisiones los temas acotados por dichas normas. En esto consiste la llamada «primacía» de la Constitución".

Este problema que plantea la primacía y la rigidez del texto constitucional se da tanto si la Constitución es un documento impuesto desde fuera o «desde arriba» por mecanismos políticos o sociales de cualquier tipo, como si se trata de un documento elaborado y puesto en vigor por procedimientos exquisitamente democráticos, ya que en éste segundo caso -se dicebastaría solo con esperar unos años, una generación, para que el documento tuviera ya la naturaleza de una imposición externa, anterior, no decidida por los interesados sino por la generación anterior. De hecho este segundo supuesto era el que estaba en la mente de algunos de los que se plantearon por primera vez el problema: el de si las generaciones pasadas pueden limitar de tal modo a las generaciones futuras, o, como lo formuló Jefferson, si los muertos tienen derecho a vincular a $\operatorname{los} \operatorname{vivos}^{10}$. En esto consiste la primera objeción democrática a la Constitución o la primera forma de la objeción democrática a la Constitución.

Al lado de ella hay, como es sabido, otra forma de la objeción que conviene distinguir de ésta. Se mezclan a veces ambas porque tanto una como otra obedecen a la misma duda: la duda que nos impele a preguntar cuál es la razón para imponer pautas externas a las mayorías políticas democráticas. Pero lo que nos demanda esta segunda pregunta o esta segunda forma de la objeción democrática son las razones que abonan que sea un grupo de jueces no elegido democráticamente, un grupo de sabios, el que imponga sobre el órgano legislativo una decisión o una limitación. Es, creo, lo que tradicionalmente se ha entendido como «objeción contramayoritaria» ${ }^{11}$. De ella, que ha suscitado una literatura muy importante, no voy a ocuparme sin

\footnotetext{
${ }^{8}$ Estas limitaciones han de presentarse como vinculantes para el legislador, y no como reglas de orientación meramente programáticas.

${ }^{9}$ La descripción de Bryce es lo bastante elocuente: «...están por encima de las otras leyes del país que regulan. El instrumento -o instrumentos- en que están contenidas estas constituciones no procede de la misma fuente que las otras leyes, es promulgado por procedimiento distinto y posee mayor fuerza. Su proclamación no corresponde a la autoridad legislativa ordinaria, sino a alguna persona o corporación superior o con poder especial. Si es susceptible de cambio, éste se llevará a efecto únicamente por dicha autoridad, persona o corporación especial. Cuando alguna de sus medidas entra en colisión con alguna otra de la ley ordinaria, prevalece la primera y la ley ordinaria debe ceder» (Bryce 1988, 10).

${ }^{10}$ Citado por Stephen Holmes (Holmes, 203, 1988)

${ }^{11}$ En la expresión clásica de Alexander Bickel (Bickel 1986)
} 
embargo aquí, aunque muchas de las cuestiones que ha sacado a la luz pueden ser también aplicadas a la primera versión de la objeción.

\section{II}

Vamos, pues, a explorar la primera objeción democrática o la primera forma de la objeción democrática. Empezaré por decir que al hacerlo nos enfrentamos con un problema que no es fácil de resolver mediante esa frecuente autocomplacencia practicada por muchos juristas neoconstitucionalistas de situar todos los valores que defendemos del lado de la Constitución $^{12}$, y todos los defectos que queremos evitar del lado de la llamada «política ordinaria». Eso sería dar las cosas por resueltas de antemano. Más bien la cuestión se suscita porque el diseño del constitucionalismo como afirmación de la primacía de los preceptos constitucionales sobre la ley democrática sacrifica algunos valores políticos a los que tendemos a dar una importancia crucial. Por ello hemos de analizar cuales son los argumentos que se dan en su favor, y si esos argumentos tienen el éxito que se ha pretendido.

Parece bastante claro que cuando abrimos esta incógnita sobre el constitucionalismo lo que realmente estamos haciendo es preguntarnos por la justificación de la Constitución misma, tanto de su contenido como de la fuerza que a sus preceptos se suele otorgar. Y hacemos bien, porque las Constituciones no siempre son tan esenciales, escrupulosas y concisas como se supone. Con frecuencia son ordenancistas y prolijas, cuando no oportunistas, con el resultado de que «atrincheran $»^{13}$ asuntos y problemas que no se ve bien por qué han de hurtarse al legislador. Una tentación muy corriente entre los que participan en un proceso constituyente es incluir en la Constitución extremos propios de sus ideales políticos o regulaciones detalladas sobre asuntos de su interés. El «momento constituyente» no es necesariamente, como se ha pretendido ${ }^{14}$, un ejercicio de imparcialidad inspirado por el interés general. Puede muy bien ser -de hecho suele ser- un periodo en el que las fuerzas sociales, políticas y económicas más relevantes forcejean para introducir en el texto constitucional la garantía rígida de sus intereses y prejuicios en el contexto de una gran turbulencia política (Elster 2000, 159). Por ejemplo, por admirable que fuera el proceso de la transición española y la elaboración de su constitución, también se dieron en él casos de este tipo, como lo fue la sombra del comportamiento militar o las pre-

\footnotetext{
${ }^{12}$ Muchos de estos juristas se pretenden críticos del positivismo jurídico al mismo tiempo que practican una suerte de ciego positivismo de la Constitución.

${ }^{13}$ Recurro a la traducción literal del verbo inglés to entrench, que es el utilizado para denotar esa protección.

${ }^{14}$ Por Bruce Ackermann, en (Ackerman 1991). Ver sobre ello en castellano (Ackerman B. \& Rosenkrantz, C 1991).
} 
siones de la iglesia católica para incluir en el texto medidas de privilegio en su favor.

Si esto es así entonces será ya definitivamente difícil considerar fundadas algunas versiones de la teoría que ve la Constitución como un «precompromiso» del tipo Ulises . En efecto, en algunas de esas versiones se ha considerado que la idea de vinculación constitucional de futuro podría explicarse acudiendo a la racionalidad que exhibe Ulises al ordenar que le aten al mástil de la nave y prohibir que le desaten previendo que el canto de las sirenas le haría débil de voluntad (Elster 1979, Holmes 1995, Moreso 2000). Pero trasladar esto a la cuestión de la Constitución y su vinculación del futuro es difícil por tres razones. En primer lugar porque ha de notarse que Ulises es la misma persona en ambos momentos, es decir, que el Ulises de hoy decide sobre sí mismo, sobre el Ulises de mañana. En el mecanismo constitucional de la vinculación hacia el futuro, por el contrario, nos encontramos con que quienes ordenan la vinculación no son generalmente los mismos que la van a sufrir. No es pues un Pedro (el sobrio) previendo los excesos futuros del mismo Pedro (pero ahora el borracho), como vino a afirmar Hayek. Se trata de individuos distintos o de generaciones distintas (Elster 2000). En segundo lugar porque Ulises, en el momento en que decide atarse, se nos aparece como un Ulises lúcido, frío e inteligente que está pensando en un futuro Ulises perturbado, dominado probablemente por las pasiones. Trasplantado a los términos constitucionales ello querría decir que los individuos de la generación constituyente se suponen sobrios, es decir, lúcidos, fríos y fuertes; y los individuos de las generaciones sucesivas se suponen borrachos, es decir, miopes, pasionales y débiles de voluntad, capaces por ello de tomar decisiones irracionales con las que se perjudiquen a sí mismos. Esto carece de justificación: pone de manifiesto una desconfianza hacia las mayorías democráticas del futuro que expresa un paternalismo en sentido estricto, es decir, un paternalismo para con los otros y no solamente un auto-paternalismo como pudiera ser el caso del ingenioso Ulises. El complejo fenómeno jurídico, político y ético del constitucionalismo vendría así a asentarse en un gigantesco acto de paternalismo para el que no saben darse razones de mayor peso que esas limitaciones de la racionalidad. Y en tercer lugar, y como he recordado antes, no solamente no está probada esa presunta lucidez del constituyente, sino que muchas veces lo que hay en las Constituciones son tomas interesadas de posición o defensa de privilegios. El contenido de lo que se protege no es, pues, lo racional frente a las pasiones, sino que muy bien puede ser al revés, lo pasional e interesado de los constituyentes que se blinda frente a la racionalidad de las futuras generaciones democráticas.

Así pues, si no damos con razonamientos más fundados que esos el constitucionalismo tendrá que batirse en retirada. Y el resultado de esa retirada es que cualquier mayoría democrática de futuro podrá prescindir de los vínculos constitucionales. Me imagino que este corolario tan tajante gusta- 
rá a pocos, pero si el partidario de la posición constitucionalista quiere evitarlo tendrá que presentar razones serias para incluir un tema en la constitución y sobre todo razones que pueden abonar que algunas instituciones y derechos sean «atrincherados» y sustraídos a la decisión democrática, es decir, llevados más allá del ámbito de la ley ordinaria y depositados fuera del alcance del legislador cotidiano. Esto es lo que tendremos que preguntarnos enseguida, pero antes conviene que hablemos un poco de la rigidez de las constituciones.

\section{III}

Para considerar cómo opera esa primacía de la constitución sobre la ley ordinaria vamos a establecer una taxonomía imaginaria de los procedimientos posibles de reforma constitucional ${ }^{15}$. En las disposiciones de reforma es donde se hospeda la mayor o menor rigidez de las constituciones y donde se ve con toda claridad esa primacía que se traduce en las limitaciones al alcance de la actividad del poder legislativo. Puede en general decirse que cuanto más fuerza se le quiere dar a la norma constitucional más limitadas resultan las competencias del legislador democrático en cuanto a su reforma. Presentaré un abanico de procedimientos de reforma que vaya descendiendo paulatinamente desde la primacía total de la norma constitucional en detrimento absoluto del principio democrático, hasta la primacía de la decisión democrática ordinaria que supone la desaparición del ideal del constitucionalismo.

1. El grado superior de esa taxonomía, es decir, el menos democrático, lo ocuparía la constitución o las normas constitucionales que prohibieran al legislador democrático su modificación o reforma. La norma constitucional se impone aquí totalmente a la ley ordinaria. Aquí no hay procedimiento de reforma posible; simplemente los preceptos se declaran intangibles. Esta técnica constitucional se utiliza para proteger principios considerados irrenunciables. La Constitución alemana, en alguna de sus interpretaciones al menos, la prevé para los derechos fundamentales y la organización federal, y la francesa para proteger la integridad del territorio y la forma republicana de gobierno. Otras, como la griega o la portuguesa también tienen o han tenido cláusulas de esta naturaleza.

2. En segundo lugar podríamos imaginar un procedimiento que encargara la reforma, o la congelación de la reforma a un órgano o autoridad no elegido democráticamente, como podría ser el rey o el Ejecutivo, mediante un veto, o sistemas parecidos. En el constitucionalismo decimonónico, en el que todavía perduraban huellas de la preeminencia de la figura del monarca, se hacía con frecuencia depender la modificación de la constitución del acuerdo del rey. Así sucede, por ejemplo en muchas de las cartas constitu-

\footnotetext{
15 Para una clasificación parecida, cfr. Farreres 2000 y Elster 2000.
} 
cionales de los pequeños estados alemanes o en la misma Constitución belga de 1831, en la que la reforma constitucional necesitaba del acuerdo real ${ }^{16}$.

3. En el tercer nivel situaré algún procedimiento extraordinariamente rígido de reforma. Por ejemplo, el procedimiento del artículo 168 de la Constitución española. En él se contienen tres requisitos consecutivos para la reforma de algunas normas constitucionales: mayoría de dos tercios en ambas Cámaras, convocatoria de nuevas elecciones y aprobación de la reforma por una nueva mayoría de dos tercios de ambas Cámaras, y referéndum de ratificación. Este precepto español es muy ilustrativo porque introduce los tres procedimientos más comunes de protección constitucional: las mayorías cualificadas, las cláusulas de enfriamiento ${ }^{17}$ y el referéndum. De la combinación de dos de estos tres procedimientos se nutren los siguientes tres grados.

4. Exigencia de mayoría cualificada unida a una cláusula de enfriamiento. Tal es el sistema básico de la reforma italiana, que demanda una aprobación de cada Cámara por mayoría absoluta o de dos tercios, y dos deliberaciones sucesivas con un intervalo no menor de tres meses.

5. Mayoría cualificada en alguna cámara legislativa, a la que después se añade un referéndum. Este podría ser el caso de algunas de una de las vías abiertas por el artículo 167 de la Constitución española, que encomienda a mayorías cualificadas en las dos cámaras la aprobación del proyecto de reforma y abre la vía a un referéndum de ratificación cuando lo soliciten una décima parte de los miembros de cualquiera de las cámaras.

6. Cláusula de enfriamiento de la propuesta de reforma, a la que se haría seguir un referéndum. En el artículo 88 de la Constitución danesa se contiene una doble cláusula de enfriamiento, temporal y orgánica, para los órganos del legislativo, pero no se requieren mayorías cualificadas. A continuación se prevé un referéndum para aprobar la propuesta.

Los siguientes tres grados usan sólo uno de esos procedimientos.

7. Exigencia única de una mayoría cualificada. Caso, por ejemplo, de la Constitución portuguesa que exige sólo una mayoría de dos tercios de los diputados para aprobar la reforma de la Constitución.

8. Decisión del órgano legislativo por mera mayoría a la que se añade, sin embargo una cláusula de enfriamiento que suponga que tal órgano ha de reconsiderar el proyecto en un momento posterior. Es el caso de Suecia, donde se exige en algunos casos una doble cláusula de enfriamiento, orgánica y temporal. Podrían pensarse en casos más sencillos de mera dilación en el tiempo.

\footnotetext{
16 Cfr. El artículo 131. Puede consultarse en Varela 1998.

${ }^{17}$ Las cláusulas de enfriamiento suelen ser de dos tipos: temporales, que simplemente obligan a posponer y reiterar la decisión en el tiempo, y orgánicas, que obligan a replantear electoralmente la composición del órgano decisorio. Las segundas, naturalmente, también dilatan la decisión en el tiempo.
} 
Exigencia simple de un referéndum de reforma.

Y por fin nos encontraríamos con aquellos grados en los que sólo actúa el órgano legislativo siguiendo su procedimiento por mayoría simple.

10. Cerca ya de la pura decisión democrática del órgano legislativo, en un sistema en el que el único requisito que se le exige al legislador para culminar una reforma es que la incorpore a una ley especialmente identificada como ley de reforma constitucional.

11. Y por fin, piénsese en el simple mecanismo de la lex posterior como fórmula de modificación de los preceptos constitucionales. Aquí puede decirse que no estamos en absoluto en el ámbito del constitucionalismo.

Merece la pena hacer algunos comentarios a esta taxonomía de mecanismos de reforma. Por lo que respecta a lo que aquí nos interesa aparecen en ella tres territorios que vale la pena diferenciar. En primer lugar tenemos los supuestos 1 y 2 en los que, bien por la intangibilidad de los preceptos bien por la extracción no democrática del órgano decisor (el rey, por ejemplo) la objeción democrática es perfectamente pertinente. Aquí el legislador democrático tiene sus competencias coartadas y limitadas por normas, valores sustantivos o derechos de veto que no puede cuestionar. En el segundo bloque (el compuesto por los números 3, 4, 5, 6, 7 y 8) nos encontramos en todos los supuestos con dos mecanismos que será necesario calibrar: las mayorías cualificadas y las cláusulas de enfriamiento. Nótese que en ninguno de ellos podemos decir que se haya hurtado la decisión al legislador democrático. Lo que se hace es introducir una serie de limitaciones a su composición y deliberaciones, muy complicadas y engorrosas en el supuesto 3 y relativamente sencillas en el supuesto 8 (puede ser una mera dilación en el tiempo de la decisión). ¿Perjudican tales limitaciones la calidad democrática de la decisión?

Como estamos presuponiendo aquí que los órganos democráticos representan fidedignamente a la sociedad y toman sus decisiones mediante el principio de mayorías, en el caso de la exigencia de mayorías cualificadas se produce sin duda una interceptación del proceso democrático así entendido, pues una minoría puede hacer triunfar su posición simplemente oponiéndose al cambio y votando la preservación del status quo. En efecto, la regla de la mayoría establece al menos dos parámetros importantes para los procesos de decisión: en primer lugar, a todos los votos les es atribuido un igual valor, con lo que a efectos del valor de su voto, todos los votantes son tratados como iguales. En segundo lugar, todas las opciones que se someten al procedimiento decisorio basado en la regla de mayoría se someten en pie de igualdad a la consideración de los votantes ${ }^{18}$. La exigencia de mayorías cualificadas ignora esos dos parámetros: da mayor valor a los votos de la minoría que no quiere la reforma constitucional, con lo que los votantes son

18 Estas afirmaciones aquí sumariamente expuestas se discuten ampliamente en Beitz 1989. 
tratados desigualmente; y se inclina claramente a favor del status quo, pues la posición minoritaria puede triunfar contra la mayoría de los votos. Por eso puede decirse que los procedimientos de decisión colectiva que exigen mayoría cualificadas no respetan los fundamentos del procedimiento democrático puro. Establecerlo para la reforma constitucional exige por tanto alegar razones suficientes para ignorar esos fundamentos.

Por lo que se refiere a las cláusulas de enfriamiento las cosas no son tan claras porque pueden ser de muchos tipos. En primer lugar nos encontramos con el mecanismo bicameral, que es al parecer el origen de la expresión ${ }^{19}$. De hecho la más común justificación de las segundas cámaras, de los Senados, fue durante el siglo XIX un argumento que apenas podía ocultar el temor hacia los órganos representativos basados en el sufragio universal. Los Senados, compuestos mayoritariamente por miembros natos en virtud de sus riquezas, títulos u honores, se decía que servían de contrapeso a los excesos de la representación popular. Esto naturalmente es presa fácil de la objeción democrática. Y es de hecho difícil concebir un «enfriamiento» que consista en someter a otro órgano diferenciado la reforma constitucional y no pugne con el principio democrático. Sólo si ambos órganos fueran estrictamente democráticos se evitaría ese corolario, pero entonces estaríamos seguramente ante una redundancia institucional. De hecho los Senados actuales suelen obedecer a otro principio que tiene que ver con la estructura federal del Estado y en cuya conformación los titulares del derecho de sufragio activo no son los individuos sino los Estados que constituyen la federación. Pero un órgano de decisión así compuesto no viola el principio democrático porque tenga competencias de «enfriamiento», sino porque no se sustenta en la regla de la mayoría de ciudadanos. Y así, una cláusula de reforma que traslade a un Senado de este tipo la aceptación de la reforma solo podría aceptarse si tal reforma tuviera como objetivo alguno de los extremos relativos a la estructura del Estado o las competencias de los miembros, pero no a otros temas como los relativos a derechos constitucionales de los ciudadanos y su garantía.

Cuando la cláusula de enfriamiento no envía el resultado de la decisión a otro órgano legitimado de otro modo, entonces puede decirse que no tropieza necesariamente con la objeción democrática. Si de lo que se trata es de someter la propuesta de reforma tras replantear electoralmente la composición del órgano decisor (suspendiendo la legislatura y convocando elecciones generales para obtener un nuevo legislativo que apruebe esa reforma), entonces no hay nada que objetar. Se trataría simplemente de autentificar o corroborar la mayoría. Si de lo que se trata es de operar un sim-

19 «Cuando Thomas Jefferson le preguntó a George Washinton por qué la convención había establecido un Senado, Washington le replicó preguntándole ‘¿Por qué vierte su café en el plato?' 'Para enfriarlo' replicó Jefferson. 'Justamente' dijo Washington 'vertemos la legislación en el plato senatorial para enfriarla’» (Elster 2000, 133). 
ple enfriamiento «temporal» por la vía de posponer la decisión un tiempo para que el mismo órgano democrático vuelva a aprobar la reforma, se trataría de un mecanismo de intensificación de la deliberación. En ambos casos la objeción democrática no procede.

El último grupo de supuestos de reforma (los englobados en los números 9,10 y 11) son perfectamente democráticos. El referéndum mediante el que los ciudadanos individual, igual y directamente deciden la aprobación o rechazo de la reforma no puede tener ninguna tacha democrática. De hecho, en el simbolismo politológico, el cuerpo decisor de los ciudadanos es frecuentemente identificado con el poder constituyente. Que tal poder cree o modifique la constitución debe ser considerado una suerte de competencia «natural». Y lo mismo puede afirmarse de los supuestos en que los representantes del cuerpo electoral constituidos en poder legislativo, por decisión expresa incorporada a una ley de reforma o por decisión tácita, proceden a la reforma de la Constitución.

Vamos a volver al hilo de nuestra argumentación y analizar qué cosas se introducen y protegen en los textos constitucionales y qué razones pueden alegarse para ello ${ }^{20}$. Con ello trataremos de profundizar en la posible justificación que pueda haber para establecer sistemas rígidos de reforma que puedan incluso pugnar con la fuerza que tiene prima facie el principio democrático.

A) En primer lugar, y como se ha sugerido ya en páginas anteriores, en las constituciones pueden incluirse asuntos perfectamente triviales que tienen que ver con las circunstancias de la elaboración de la constitución o con los avatares históricos del país en cuestión. Sin ánimo exhaustivo ofreceré algunos ejemplos. En la Constitución Francesa (artículo 2) se impone «La Marsellesa» como himno nacional. En la Constitución española los colores de la bandera, que se protegen además con el procedimiento más rígido de reforma. En la Constitución finlandesa (artículo 72) se establecía el marco como unidad monetaria, con lo que la entrada en la economía del euro habrá exigido una reforma constitucional. En la Constitución alemana se eleva a rango constitucional la competencia de los Länder sobre el impuesto que grava la cerveza. En la Constitución austriaca se atribuye a la federación plenamente lo relativo a escuelas forestales. Y en la Constitución griega (artículo 3,3) se dice que «el texto de las Sagradas escrituras es inalterable, su traducción oficial en otra forma de lenguaje, sin el consentimiento previo de la Iglesia autocéfala de Constantinopla, está prohibida», por no mencionar que en el artículo 59 se constitucionaliza la fórmula del jura-

\footnotetext{
${ }^{20}$ Utilizo aquí, aunque con distinto orden y ampliado, un esquema propuesto por Sunstein (Sunstein 1991, 636 y ss).
} 
mento de los cargos públicos «en nombre de la Santa Trinidad Consustancial e Indivisible» ${ }^{21}$.

Es evidente que todos estos artículos, y muchos más que podrían mencionarse, no deberían ser sometidos a ninguna exigencia que fuera más allá de la decisión democrática del poder legislativo constituido, porque cualquier otra protección para-democrática carecería de justificación.

B) En segundo lugar suelen también introducirse en los textos constitucionales, para evitar su discusión cotidiana en la política ordinaria, aquellas cuestiones tan sumamente controvertidas e imposibles que pueden hacer peligrar el proyecto político como un todo. De ese modo se hace desaparecer de la discusión pública algún tema que se considera peligroso para la estabilidad de la polis. Se apela así a las llamadas «reglas de mordaza» (Gag rules), que pueden ser definidas como reglas que acuerdan una autocensura estratégica para evitar divisiones irreconciliables (Holmes 1988, 19). La Constitución sería aquí el lugar donde se acordara extraer de los avatares de mayorías y minorías y del calor de las controversias extremos sobre los que la sociedad está tan dividida o un sector poderoso de la misma considera tan intocables que permitir que salgan a la arena política y se sometan al voto mayoritario -se dice- podría dar al traste con toda la empresa política. Hay muchos ejemplos, más o menos convincentes, de una estrategia semejante. Creo que puede afirmarse que la idea de la separación Iglesia/Estado y el principio de abandonar la instauración de una religión oficial pudo obedecer inicialmente a una estrategia de este tipo. Para acabar con las guerras de religión lo mejor es extraer la religión de la controversia política ${ }^{22}$. Pero también hay supuestos en que grupos sociales o políticos fuertes imponen esa mordaza en la constitución para no ver en peligro una posición hegemónica. Por paradoja, tal ha sido también en la historia de muchos países el caso mismo de la religión mayoritaria. En la Constitución española se sometió a una práctica regla de autocensura la forma de gobierno y la llamada unidad de España. El ejemplo de la esclavitud en la Constitución americana siempre se trae a colación. Pero hay situaciones mucho más amargas: la impunidad de dictadores y presuntos genocidas obtenida a cambio de no impedir procesos de transición en ciernes, por ejemplo.

La justificación de esta manera de obrar parece obedecer a una lógica consecuencialista, y constituye un ejemplo de lo que se ha venido llamando desde Weber «ética de la responsabilidad». Si se ha de «fundar»o «constituir» de nuevo la comunidad política, o culminar con éxito un proceso de

21 Tomo los datos constitucionales de Las Constituciones de los Estados de la Unión Europea (Edición de Germán Gómez Orfanel) Madrid. Centro de Estudios Constitucionales. 1996. Las reformas de algunos artículos de esas constituciones no afecta al argumento.

22 «Y dado también que en materia religiosa forzar las conciencias se ha demostrado frecuentemente como peligroso en los países en que esto se ha llevado a cabo y con el fin de asegurar un gobierno más tranquilo y pacífico en esta provincia.....» Acta de Tolerancia (Maryland). 1649. 
transición a la democracia, y eso se considera un estado de cosas bueno o justo, entonces hay que hacer ciertas concesiones a los poderes fácticos en presencia, y esas concesiones aparecerán sin duda en la Constitución como conclusiones no discutibles, o extremadamente difíciles de discutir, por estar sometidas a procedimientos muy rígidos de reforma constitucional. Pero es preciso distinguir entre aquellos temas que, como la exclusión de la religión de Estado, consideramos justificado que se extraigan de la discusión pública y se silencien por disposición constitucional, sea cual sea la circunstancia política en que se encuentre la comunidad, y aquellos otros que, como la imposición de hecho de las preferencias o prejuicios del estamento militar o eclesiástico, no consideraríamos justificado constitucionalizar y atrincherar, salvo en virtud del hecho de que aparecen como condiciones necesarias para el establecimiento del proceso democrático. Esto último solo puede ser concebido como una situación provisional en la que la democracia está de algún modo tutelada, o es todavía deficitaria.

Ello quiere decir que las razones aceptables para constitucionalizar y atrincherar algunos extremos han de ser razones sustantivas anteriores a cualesquiera circunstancias contingentes de la comunidad política. Y si son razones de suficiente calado entonces podrán incluso imponerse a la decisión democrática, pero si no lo son, no debemos aceptar que sean protegidas por ninguna rigidez constitucional. También las constituciones pueden ser justas o injustas. Una Constitución que establezca la tolerancia religiosa es justa aun cuando no haya sido adoptada democráticamente, pero una Constitución que impide el procesamiento de un dictador por delitos probados es injusta, aunque sea el producto de una deliberación y reflexión muy democrática.

C) En tercer lugar, se ha afirmado que la Constitución sería un lugar idóneo para dar respuesta a algunos de los que se llaman técnicamente problemas de acción colectiva como problemas del tipo «dilema del prisionero», y que se suscitan con frecuencia en la vida política. Como es sabido, cuando una pluralidad de actores con intereses enfrentados actúan en contextos estratégicos, las decisiones a las que se ven impulsados por la racionalidad instrumental acaban por producir resultados que no son los mejores para ellos. Se suele poner como ejemplo de una situación semejante la «Cláusula de Comercio» de la Constitución Americana, que prohíbe a los Estados de la Unión establecer regulaciones aduaneras al comercio interestatal. Escribe así Sunstein justificándolo: «...a la luz de las fuertes actitudes emocionales que alimentan las percepciones del interés del propio Estado, un sistema en el que cada Estado pueda elegir si iniciar medidas proteccionistas podría llevar a muchos Estados a hacerlo. Pero un acuerdo de todos los Estados para rechazar el proteccionismo y renunciar así a su derecho anterior derivado de los artículos de la Confederación, promovería el interés colectivo» (Sunstein 1991, 641). Supongo que una consideración semejante ha llevado al constituyente español a establecer en el artículo 157, 2 que 
«las Comunidades Autónomas no podrán en ningún caso adoptar medidas tributarias...que supongan obstáculo para la libre circulación de mercancías o servicios». El hecho de que algunas de esas actitudes emocionales puedan impeler a algunas autoridades autonómicas a imponer aranceles proteccionistas en su propio beneficio provocaría inmediatamente la generalización del proteccionismo y como consecuencia de ello el desastre económico tanto para el conjunto como para cada una de las comunidades autónomas. Supongamos que, efectivamente, un sistema en el que la falta de cooperación en materia de aranceles aduaneros entre las regiones genera un grave desajuste económico. Es más, si una comunidad lo hubiera establecido para sí misma en solitario, el sistema hubiera sido bueno económicamente para ella, pero al actuar en un contexto estratégico todas las demás comunidades adoptarán asimismo la medida y se producirá el desastre colectivo. Pues bien, si esto es así ¿cuál es la razón para prohibirlo en la Constitución? ¿la mera ineficiencia económica? ¿la corrección de las limitaciones de la racionalidad de los actores políticos? No es nada seguro que eso pueda considerarse una razón suficiente. Si algún Estado o región afirmara, por ejemplo, que el derecho a imponer tributos forma parte de su propia identidad política y expresa de modo irrenunciable el nivel de autogobierno que quiere ejercer, no habría mucho que añadir desde esos puntos de vista. Podrá ser advertida de los inconvenientes económicos de ejercer ese derecho, pero no podría serle discutido apelando solo a términos de pura economía. Muchos actores políticos prefieren mantener la titularidad y el ejercicio de algunos derechos que consideran moralmente importantes aunque el precio que tengan que pagar en términos instrumentales sea alto. $\mathrm{Y}$ a ese razonamiento solo puede oponerse un argumento que se sitúe en su mismo nivel. Por ejemplo, podría argüirse que aquella cláusula constitucional no es sino una concreción de otras que pretenden asegurar ciertos derechos de libertad de los ciudadanos, derechos que la justifican a ella y a un precepto como el del artículo 139,2 de la Constitución que afirma que «Ninguna autoridad podrá adoptar medidas que directa o indirectamente obstaculicen la libertad de circulación y establecimiento de las personas y la libre circulación de bienes en todo el territorio español». O podría argüirse que aquella cláusula vigila que a todos los ciudadanos se les reconozca un derecho básico a ser tratados del mismo modo por la ley, y que eso la justificaría a ella y también a un precepto como el del artículo 139,1 que dice que «Todos los españoles tienen los mismos derechos y obligaciones en cualquier parte del territorio nacional». Y -así seguiría el razonamiento- esos mencionados derechos de libertad o a un tratamiento igual son derechos que van más allá de la mera vigilancia al tráfico mercantil, y que también son más importantes que los presuntos derechos de las Comunidades Autónomas, de forma tal que ninguna de ellas tendría legitimidad ni fundamento para desconocerlos.

En resumen, que quizás la idea de que ciertas normas sirvan para resolver problemas de acción colectiva y aseguren la eficiencia en determinadas 
interacciones no es suficiente base para constitucionalizarlas. Es efectivamente posible que un mecanismo como la protección constitucional no tenga por qué obedecer a demandas de racionalidad instrumental de los actores políticos o de los ciudadanos. Por supuesto que ello no significa que no sea bueno y útil establecer jurídicamente, incluso constitucionalmente, cláusulas de ese tipo; significa solo que su excesivo «atrincheramiento» no tiene una justificación lo suficientemente fundada. Bastará para su protección establecer algunas cláusulas de enfriamiento que incrementen la atención deliberativa de los órganos democráticos, pero no una sobreprotección. Seguramente sucede aquí lo mismo que hemos visto en el supuesto anterior: solo nos convence la decisión constitucional si lo que subyace a ella son razones sustantivas que se sitúan por encima de las conveniencias de presente o de futuro: por ejemplo, razones que apelan a la protección de derechos individuales.

D) En cuarto lugar, es casi un axioma histórico identificar a una constitución porque incorpora ciertas coordenadas y pilares que definen la estructura misma del Estado. Cosas tales como la separación de poderes, la estructura territorial, la forma del poder legislativo, algunas exigencias y cautelas de los procedimientos decisorios, el veto de unos órganos sobre otros, etc... vienen así a ser incorporadas a un texto normativo de jerarquía superior y protegidas frente al mayoritarismo. Y en efecto, toda Constitución incluye lo que se denomina una «parte orgánica» que versa sobre la articulación de los poderes, su funcionamiento y sus límites. Y ello, tal y como estamos viendo, significa a la postre que una «generación», la de los constituyentes, limita el alcance de la decisión democrática de una generación futura sin que para ello se hayan ofrecido razones satisfactorias. Es pues también susceptible de ser interrogada desde la «objeción democrática».

¿Qué podemos aducir en favor de ese «atrincheramiento» constitucional? Evidentemente no es posible introducirse aquí en la fundamentación pormenorizada de cada una de las instituciones que se incorporan a los textos constitucionales, pero quizás sí sea posible arriesgar un esquema metódico general que nos ayude a comprender el sentido de la cuestión. Para hacerlo es preciso establecer una distinción clara entre lo que pueden llamarse principios o exigencias ético-políticas y lo que llamaré mecanismos institucionales ${ }^{23}$. Esta distinción es importante, pero muchas veces se desconoce en la práctica; por ejemplo, se habla con frecuencia del «principio» de separación de poderes o del «principio» federal como si se tratara de exigencias éticas o políticas, cuando en realidad estamos simplemente ante dos

${ }^{23}$ Llamó mi atención sobre esta distinción Robert Summers en una conversación privada. No me parece ajena a la diferencia analítica que establece Elster entre reasons for precommitment y devices for precommitment (Elster 2000). Utilizo aquí la expresión principios en el sentido de enunciados que suministran «razones» o «justificaciones» pero no en el sentido más técnico usual hoy en el debate académico. 
construcciones institucionales, ante dos «mecanismos». La distinción nos ayudará a encontrar la posible justificación de esa incorporación constitucional. La articulación normativa de algunos poderes y algunas particularidades que se contienen en ella necesitan también de una justificación para ser incorporadas y «atrincheradas» en los textos constitucionales, y esa justificación solo la pueden dar los «principios» entendidos como razones éticas y políticas. Así, los que he llamado mecanismos institucionales tendrían su razón de ser en que son articulaciones normativas que desarrollan o sirven de vehículo a la realización de los principios. Trasladado al lenguaje quizás más expresivo de Elster, las razones para el precompromiso constitucional justificarían los mecanismos de precompromiso, de forma tal que las construcciones institucionales y su protección constitucional tuvieran que exhibir las razones que los apoyan. Y entonces nuestra estrategia tendría simplemente que consistir en preguntar por esas razones y seleccionar aquellas que fueran lo suficientemente convincentes como para superponerse a aquellas que subyacen al principio democrático. Si nos preguntáramos por ejemplo por la justificación del mecanismo normativo de la separación de poderes podríamos aducir con cierta plausibilidad la exigencia de independencia judicial para la protección de los derechos individuales frente al poder ejecutivo, pero si nos interrogásemos sobre la conveniencia de constitucionalizar, por ejemplo, el déficit cero o la independencia del banco central, seguramente no nos sentiríamos satisfechos porque algunos economistas nos dijeran que las mayorías toman sus decisiones con tendenciosidad o con miopía de futuro.

Como no es posible desarrollar un argumento similar institución por institución me limitaré a ofrecerles mi conclusión anticipada. Pienso que solo los principios o razones que recogen derechos individuales básicos o descansan en ellos son lo suficientemente poderosos como para medirse con la objeción contramayoritaria. La constitucionalización de mecanismos que incrementen la racionalidad instrumental de las decisiones, superando la desviación a que empujan las pasiones, los intereses sectoriales o la miopía temporal solo podría aceptarse si, como hemos visto en el caso anterior, se llevara a cabo sólo mediante cláusulas de enfriamiento. Solo cuando esas instituciones fueran un medio para el reconocimiento y la garantía de derechos individuales ${ }^{24}$ podría irse más allá.

E) En quinto lugar, es convicción común que las Constituciones han de reconocer, formular y garantizar los derechos individuales básicos, que se vienen denominando derechos humanos o derechos fundamentales. Si hay algún extremo en el que el consenso sea casi unánime es éste ${ }^{25}$. Recurrien-

24 También podría argumentarse que algunas de esas instituciones o mecanismos son «bienes públicos» que se pueden concebir como condiciones necesarias para la satisfacción de ciertos derechos individuales.

25 Digo «casi» porque como es sabido una cierta posición teórica apuesta más bien por el diseño constitucional a base de mecanismos y se muestra reticente ante una declaración formal 
do a la venerable idea de John Locke, puede decirse que los gobiernos y los Estados tienen su razón de ser en la protección de derechos individuales anteriores a ellos y al derecho positivo. En consecuencia, el documento solemne mediante el que se constituye una unidad política tiene que llevar en su frontispicio la misión de reconocer y proteger tales derechos. Esta idea propia del iusnaturalismo moderno de que hay derechos naturales anteriores a la comunidad política, puede hoy ser también aceptada, sin esas adherencias iusnaturalistas, recurriendo a una concepción de la Justicia entendida como un segmento de la moralidad o de la ética que se expresa a través de derechos morales individuales anteriores a cualquier establecimiento o incorporación al derecho positivo. Si se acepta esto, entonces puede concluirse que la Constitución de una comunidad política ha de reconocer y garantizar como derechos fundamentales aquellos derechos morales previos. La justificación de esa incorporación y especial «atrincheramiento» sería precisamente la apelación a la Justicia como complejo de razones morales justificatorias.

Los tipos de derechos que suelen incorporarse y protegerse en las constituciones como derechos fundamentales son variados, y no es este el momento de hacer una taxonomía de los mismos, pero es importante reflexionar sobre la naturaleza de algunos de ellos porque suelen presentarse como el más característico baluarte constitucional frente a las mayorías, como cartas de triunfo frente a la decisión mayoritaria. Hay en primer lugar derechos que se presentan como postulados morales «pre-políticos» sencillamente porque se sitúan o pretenden situarse más allá del alcance de cualquier poder público, sea democrático o no lo sea. En ellos el «atrincheramiento» constitucional quiere expresar tan solo que el poder político no debe invadir la esfera que protegen esos derechos. Pongamos el caso de la prohibición de la esclavitud, la interdicción de la tortura o la prohibición de cualquier tipo de discriminación racial. Incluso algunos de esos llamados tradicionalmente derechos de la personalidad: la libertad de elección de compañero sentimental, por ejemplo. Lo que se quiere afirmar constitucionalmente con derechos de este tipo es que, como una cuestión de principio, las mayorías o quienquiera que ejerza el poder mediante normas jurídicas no tiene ninguna competencia para entrar en esa materia para regular, matizar, limitar, etc. Utilizando el lenguaje hohfeldiano se trataría de establecer una inmunidad absoluta frente al poder jurídico y político. El ciudadano se torna a estos efectos inmune a cualquier pretensión del legislador, que, en consecuencia, tiene prohibido constitucionalmente el interferir en esa esfera. Y si se declara hoy para el futuro es porque no se contempla ninguna po-

de derechos. No es desde luego nada nuevo, pues puede encontrarse ya en las discusiones de El Federalista $n$. 83 (Hamilton). En la actualidad esto es tema de debate alrededor de propuestas como Charter 88, diseñada para la incorporación de un Bill of Rights al entramado del derecho constitucional inglés. 
sibilidad de que en el futuro las cosas puedan ser de otro modo, diga lo que diga la mayoría democrática. Podría argüirse entonces que, por definición, la objeción democrática no concierne a esta protección constitucional, porque el hecho de que el poder sea democrático o no lo sea es irrelevante cuando se trata de interferir con ellos. Este es el supuesto más claro en el que cabe pensar en un atrincheramiento constitucional serio mediante cláusulas intangibles o métodos de reforma extraordinariamente complejos. En segundo lugar nos encontramos con algunos de los derechos que fundamentan los mecanismos institucionales que hemos visto en el apartado anterior. Por ejemplo, el derecho a la justicia o a «la tutela efectiva de los jueces y tribunales», o el derecho a participar en los asuntos públicos, que están en la base y son las precondiciones del diseño de la estructura de grandes poderes del Estado, como el poder judicial y el poder legislativo. El atrincheramiento constitucional de esos derechos obedece seguramente a su condición de puntos de apoyo del edificio institucional, en el sentido de que cabe pensar que los seres humanos optan por construir la comunidad política con sus poderes coactivos a condición, por ejemplo, de que sus conflictos sean resueltos eficaz e imparcialmente y que puedan participar en la elaboración de las leyes que se les van a aplicar. Y puede entonces suponerse que sería contrario al propósito mismo de tales mecanismos institucionales el que fuera posible alterar los mismos puntos de apoyo en que se basan mediante, por ejemplo, una decisión mayoritaria. Las mayorías, en ese caso, traicionarían el fundamento mismo que las sustenta como órgano de decisión política, y así, del mismo modo que hemos visto que se hurtan a la decisión mayoritaria aquellos ingredientes del aparato institucional que sean mecanismos aptos para hacer efectivos o garantizar esos derechos -por ejemplo, la independencia del juez o la publicidad del proceso-, se hurtarían a ella con más razón los derechos mismos que les sirven de fundamento. Aquí podría pensarse en una cierta rigidez constitucional mediante fórmulas complejas. Y en tercer lugar tenemos ante nosotros aquellos derechos, llamados comúnmente, aunque a veces no del todo con propiedad, derechos de prestación que no solo se garantizan y satisfacen con un reconocimiento jurídico, sino que necesitan para ello de todo un conjunto de infraestructuras y actividades económicas y sociales capaces de proveer a los titulares con aquellos bienes que son condición para esa satisfacción. La particularidad de estos derechos es, en efecto, que se violan sobre todo por omisión, por la omisión de aquellas acciones sociales y económicas necesarias para satisfacerlos. En relación con ellos se acepta comúnmente que toda la trama de leyes y disposiciones que son necesarias para hacer posible su garantía real sean competencia del poder legislativo mediante sus decisiones mayoritarias cotidianas, es decir, se acepta comúnmente que no se atrincheren. Las razones para ello tienen que ver seguramente más con la complejidad de las políticas públicas necesarias para vehicular su cumplimiento que con su pretendida controvertibilidad, pero ese es un tema que no es necesario abor- 
dar aquí. Sin embargo hay algunos de ellos que han alcanzado un status especial porque su importancia para el desarrollo de la personalidad individual o para la satisfacción de otros derechos es tal que se acepta que algunos extremos de los mismos han de ser protegidos y atrincherados. Así sucede en algunas constituciones con el derecho a la educación o con los sistemas de salud pública.

Más allá de cualquier consideración pormenorizada de tipos de derechos, podría afirmarse como conclusión general que los límites y compromisos previos que se imponen al poder de las mayorías se fundamentan directa o indirectamente en el valor que atribuimos al ciudadano como individuo libre y autónomo, definido a través de sus derechos. Como ha escrito Richard Kay: «El constitucionalismo es ... una expresión de aquella visión que acabó por ser conocida como liberalismo - la idea de que la unidad moral relevante en el discurso político es el individuo, o, quizás más rigurosamente, que la polis misma no tiene entidad moral independiente de la de sus miembros. Una premisa básica de esta perspectiva es que la más alta satisfacción humana solo puede darse en una vida libremente elegida» (Kay 1998,19). Y esto, naturalmente, es lo que viene a proteger la Constitución frente a las mayorías electorales.

\section{V}

La Constitución, por tanto, parece tener como contenido más característico el de proteger de las incursiones de la mayoría el ámbito de un «coto vedado $»^{26}$, que está compuesto básicamente por derechos fundamentales y por aquellos mecanismos institucionales que puedan ser condición para la garantía de esos derechos fundamentales. Y aquí es precisamente donde se origina la gran pregunta que suscita la «objeción democrática» o, para expresarlo en otros términos, «la gran fractura entre democracia y constitucionalismo» (Fioravanti 2001,163). De algunos de sus aspectos me voy a ocupar a continuación ${ }^{27}$.

Quien ha planteado en los últimos años con más fuerza la objeción en esos términos ha sido Jeremy Waldron, en una propuesta teórica que trata de recordar que el mundo político no solo exige de los filósofos una teoría de la justicia, sino también una teoría de la autoridad. «Uno de los grandes problemas de la filosofía política»-escribe- «es explicar como puede haber una sociedad que se ordena y se gobierna a sí misma, que toma iniciativas y que funciona como un agente, dada la pluralidad de sus miembros y los desacuerdos que tienen entre sí sobre la pregunta de qué es lo que ha de hacerse» (Waldron 1993, 31). Eso es lo que el autor llama «circunstancias de la política»: la necesidad de tomar una decisión común y la existencia de

\footnotetext{
${ }^{26}$ Expresión acuñada por Garzón Valdés en Representación y Democracia (Garzón Valdés 1989).

${ }^{27}$ Para un análisis más completo remito a Juan Carlos Bayón (Bayón 2000).
} 
desacuerdos importantes sobre el contenido y el alcance que haya de tener. En esas «circunstancias» el método de decisión que se ha impuesto en las sociedades modernas ha sido el método o procedimiento democrático: se discute libremente y se acuerda la decisión por mayoría. ¿Cuál es la justificación de semejante método? Pues una consideración de los seres humanos como seres reflexivos y autónomos, capaces de diseñar su vida y de ponerse en el lugar de los demás, aptos para tomar parte en una discusión racional sobre medios y metas en la que se respete los puntos de vista de otros, y dispuestos a comprometerse con sus propias decisiones reflexivas. Y si preferimos el procedimiento democrático de toma de decisiones es porque pensamos que esos individuos tienen un derecho a participar en aquello que va a afectar a sus vidas y a tomar parte en aquellas decisiones que establezcan los medios para resolver los problemas de la comunidad. Y ello solo puede concebirse si se piensa que están dotados de la racionalidad y el carácter suficiente para incorporarse a esa reflexión colectiva sobre las medidas y reglas necesarias para ordenar y gobernar unitariamente esa sociedad.

Pero el problema es que ese mismo fundamento es el que subyace precisamente a la idea de los derechos básicos. De nuevo Waldron: «...la idea de los derechos esta basada en una visión del individuo humano como un agente esencialmente pensante, dotado de una capacidad para la deliberación moral, para ver las cosas desde el punto de vista de los otros, y para trascender su preocupación por sus intereses propios y sectoriales. La atribución de cualquier derecho, digo, es típicamente un acto de fe en el actuar y en la capacidad para el pensamiento moral de cada uno de los individuos concernidos» (Waldron 1999, 250). Y aquí es precisamente donde está la fuerza de la objeción democrática. Si esto es así ¿por qué hurtamos a la decisión democrática las cuestiones constitucionales relativas a derechos? ¿No supone ello negar a los individuos precisamente un derecho fundamental a la participación (el derecho de los derechos (Ibíd. 232)? ¿Podemos afirmar los derechos básicos mediante el expediente de poner en cuestión el fundamento mismo de esos derechos al «atrincherarlos» frente a la reflexión y la decisión de ese mismo individuo al que se los reconocemos? La respuesta pareciera ser que el «coto vedado» es la negación de la capacidad de cada individuo de reflexionar y decidir sobre el propio «coto vedado», y ello supone tratarle como un menor o un incompetente. Pero si es un menor o un incompetente ¿por qué le atribuimos los derechos del «coto vedado»? Solo la decisión democrática en la que todos participan respeta los fundamentos en que se basan los derechos individuales. Por tanto, sobreproteger y atrincherar los derechos en una constitución inflexible inaccesible al voto ciudadano es contrario al propio fundamento de esos derechos.

La fuerza del argumento obliga a replantearse aquellas relaciones entre ley y Constitución a que antes me refería, e iniciar un movimiento en favor de la «pleamar» de la ley y la ubicación de los temas constitucionales atrincherados en sus justos límites. El problema es ahora determinar cuáles son 
esos límites, porque la lógica de la objeción invita a pensar que cualquiera de las materias susceptibles de ser incorporadas a un texto constitucional, dada su complejidad e importancia para la vida del grupo, puede ser objeto de discusiones y pugnas, es decir, puede estar aquejada por esa presencia de «desacuerdo» que constituye una de las circunstancias que hacían necesario el procedimiento democrático de decisión. Y de conformidad con esa lógica todo sería entonces reconducible a la competencia del legislador y no habría por qué atrincherar nada.

Recordemos, sin embargo, que estamos hablando solamente de la primera forma de la objeción democrática, es decir, de aquella que trata de enfrentar las condiciones de rigidez de la constitución frente a su propio cambio y reforma. Y como hemos visto, existe una panoplia de métodos de reforma: referéndum, cláusulas de enfriamiento, ley ordinaria de reforma, que cumplen perfectamente con la exigencia democrática, sin necesidad de entregar las cláusulas constitucionales al mero mecanismo de la derogación tácita de acuerdo con el principio lex posterior. Esta formulación de la objeción democrática, por tanto, solo sería aplicable a las cláusulas constitucionales intangibles, es decir, irreformables, y a aquellas para las que se prevén métodos de reforma, como el veto, la intervención de órganos no democráticos o las mayorías excesivamente cualificadas, que ignoran el valor igual de cada ciudadano y su voto en las decisiones democráticas. ¿Hay cláusulas constitucionales de esta naturaleza? O, para hacer más amplia la pregunta, ¿hay algunas materias que merezcan el atrincheramiento o la protección constitucional «antidemocrática» o un atrincheramiento o protección constitucional democrática pero muy difícil de operar ${ }^{28}$ ? La respuesta no puede ser tan contundentemente negativa como podría suponer un partidario de la objeción democrática.

Para mostrar hasta qué punto esto es así no solo podrían recordarse algunas de esas disposiciones constitucionales que, como la prohibición de la esclavitud, parece imposible pensar que puedan ser derogadas o modificadas por ningún motivo. Los partidarios de la objeción podrían argüir que puede haber desacuerdos sobre el alcance de la prohibición o sobre la naturaleza de ese derecho, no solo para limitarlo, sino también para ampliarlo, y en ese caso la mayoría sería la única autorizada para deliberar y decidir. Pero también pueden hacérsele algunas preguntas a esa misma objeción democrática para ver si pueden obtenerse de ella algunas dimensiones del constitucionalismo. Ello pondrá de manifiesto que dentro de esa objeción hay algunos problemas cuya solución puede depender de un atrincheramiento constitucional de algunos extremos.

\footnotetext{
${ }^{28}$ Como hemos visto, con una combinación de cláusulas de enfriamiento orgánicas y temporales y de referéndum se puede establecer un procedimiento de reforma que sea democrático pero extremadamente difícil de llevar a la práctica.
} 
A) Hay algunas cosas que el procedimiento democrático no puede establecer por razones lógicas: el ámbito para el que la decisión se va a tomar y el universo de aquellos que han de tomar parte en el procedimiento, es decir, la identificación de quienes han de votar y decidir. Son dos cosas que se hallan, por así decirlo, en un momento anterior a que se ponga en marcha la maquinaria del proceso democrático. Una de las llamadas por Waldron «circunstancias de la política» es que exista una entidad humana colectiva, un grupo, un demos, que se vea en la necesidad de resolver un problema común. Pero esta «circunstancia» oculta dentro de sí una importante presuposición: que existe ya ese grupo o demos y alguien ha determinado ya que ese problema es común. Pero ¿cómo sabemos todo esto? ¿quién lo ha decidido? y ¿cómo se ha decidido? ¿acaso mediante el procedimiento democrático mismo? Las espinosas cuestiones de ámbito de la democracia no pueden ser resueltas por el mismo procedimiento democrático porque el establecimiento de ese procedimiento presupone ya que hemos determinado de algún modo el ámbito al que se va a aplicar ${ }^{29}$. Pues bien, este mismo argumento le es también aplicable a la pregunta por quienes son los titulares del derecho a participar. Es obvio que no podemos dejar su respuesta a un procedimiento en el que tengan derecho a participar estos o aquellos porque eso sería una petición de principio. La respuesta a la pregunta «¿quién debe votar?» no puede ser sino que debe votar aquel que «tenga derecho a votar», lo que significa que ese derecho es anterior al procedimiento. Debemos pues aducir razones sustantivas: la autonomía de la persona, la igualdad de todos, la pertenencia a la comunidad como ciudadano, los derechos a aceptar o rechazar normas que me van a ser impuestas, etc. Es decir, tenemos que dibujar un perfil de rasgos identificatorios que definan a los titulares de ese derecho antes de que el procedimiento se ponga en marcha. Y el mejor modo de hacerlo es mediante un haz de derechos individuales basados en una concepción sustantiva, no procedimental, de esos derechos. Pero si esos derechos son necesarios para la existencia de un procedimiento tan importante, parecería lógico que los protegiéramos del funcionamiento mismo del procedimiento situándolos en un espacio al que el mecanismo democrático no tuviera fácil acceso.

B) Veamos ahora el segundo argumento. El primero nos muestra que la objeción democrática no puede prescindir tan fácilmente de una teoría sustantiva de los derechos. Este segundo pone de manifiesto que la objeción democrática puede ir demasiado lejos, hasta el punto de quedar presa de su propia lógica. ¿Cuál es el fundamento del procedimiento democrático? Pues como hemos visto se trata de un «derecho a participar». Según Waldron es

${ }^{29}$ Sobre cuestiones de ámbito de la democracia remito a un trabajo de Alfonso Ruiz Miguel en el que entre otras cosas se reconocía ya su relevancia constitucional: «En muchos casos, las decisiones sobre el ámbito de la democracia se adoptan de manera expresa, típicamente -como prueba de su importancia- mediante normas constitucionales» (Ruiz Miguel 1989, 105) 
una exigencia de que la propia voz sea oída en la decisión pública en términos de igualdad: «...cada individuo demanda el derecho a tomar su parte, junto a la igual parte tomada por todos los otros individuos, en el gobierno de la sociedad. Como portador de derechos exige que su voz sea oída y que cuente en la elaboración de la decisión pública» (Waldron 1999, 236, cursiva del autor). Cuando alguien no participa de ese modo se le ha negado su cualidad plena de ciudadano. Por eso la objeción democrática nos habla de unos «muertos» (los constituyentes) que excluyen de sus derechos a unos vivos (las generaciones subsiguientes). Y aquí es donde puede estar el talón de Aquiles de esa objeción. Nótese, en efecto, que, desde Jefferson mismo, la objeción suele ser formulada en términos de «generaciones», y viene a afirmar, literalmente, que una generación no tiene derecho a vincular a la generación siguiente ni a privar a sus individuos de su derecho pleno a participar $^{30}$. Pero ¿por qué recurrir a una entidad tan confusa y problemática como la «generación»? Quienes tienen los derechos no son las generaciones sino los individuos. Son ellos los que tienen el derecho a decidir sobre los contenidos y las reformas de su Constitución. Y también de sus leyes. Así que la objeción debería ser reformulada en términos individuales. Pero si los hacemos acabaremos en conclusiones difíciles de aceptar. Porque en efecto, incluso si presuponemos que los individuos tienen ese derecho, por ejemplo, sólo a partir de los 18 años, todos los días hay alguien que cumple 18 años. Pues bien, en sentido estricto, a partir de ese momento todas las decisiones constitucionales o legales (directas o representativas) tomadas antes pero que ahora le afectan y todas las decisiones constitucionales o legales que vayan a tomarse en el futuro tendrían que estar sujetas a la exigencia de «que su voz sea oída y que cuente en la elaboración de la decisión pública»; es decir, en virtud del fundamento mismo de la objeción democrática ese nuevo ciudadano podría exigirnos que reabriéramos todo el proceso decisorio porque si no lo hiciéramos estaríamos traicionando los presupuestos de que decimos partir. Pero si lo demandara nos sentiríamos seguramente tentados a decirle que esperara hasta las próximas elecciones o hasta el próximo proceso constituyente para hacer oír su voz. ¿Qué razones podríamos darle para que aceptara esa espera? No desde luego que ha habido un procedimiento democrático en el que unos ciudadanos anteriores a él han tomado una decisión porque eso es precisamente lo que cancela la objeción democrática.

Acabaríamos por concluir que para respetar el derecho a participar de cada uno en los términos estrictos de la objeción sería necesario reabrir el proceso decisorio. Y como todos los días habría algún ciudadano en esta situación, eso sería tanto como mantener permanentemente abierto ese pro-

\footnotetext{
${ }^{30}$ Esta terminología es usada hasta hoy mismo cuando se debate la objeción democrática. Como prueba, el continuo uso de la idea de generaciones por parte de Víctor Ferreres (Ferreres 2000 , p.35 y 36 ).
} 
ceso. $\mathrm{Y}$ en ese caso terminaríamos por no decidir nunca y con ello por hacer imposible la posibilidad de gobernarnos mediante reglas. Tendríamos entonces que contra-argumentar que medidas como reabrir diariamente las constituciones vigentes o las cuestiones ya decididas o los procedimientos para conformar los órganos de decisión supondrían tanto como no tener constitución alguna ni tomar decisión alguna, porque una perpetua deliberación ni es una constitución ni es una decisión, y un órgano decisorio en permanente proceso de formación no es un órgano decisorio. Y esto equivaldría a decir que al menos alguna decisión anterior ha de tener normalmente un periodo de vida en que regule las conductas de los ciudadanos sin que pueda ser puesta en cuestión por otra mayoría. Es decir habríamos de hablarle de que las normas por las que se ordena la sociedad han de tener otras propiedades además de la de ser democráticas en su origen: por ejemplo, deben disfrutar de una cierta estabilidad, ser públicas, no ser retroactivas, etc... que son todos ellos rasgos que no son pura formalidad ajena a los derechos, sino que son precisamente condiciones para el desarrollo y la garantía de la mayoría de esos derechos, y desde luego son condición necesaria para poder desarrollar una existencia como ser que piensa y reflexiona, es capaz de proyectar su propia vida y desarrollar su personalidad en libertad. Es más, podríamos incluso recordarle que la aplicación estricta de la objeción democrática supondría inmediatamente la desactivación del mecanismo democrático mismo, porque nada podría articularse como «constituyente» ni como «legislador» si sus decisiones hubieran de ser reabiertas incesantemente. Por eso es por lo que puede afirmarse que la objeción democrática va demasiado lejos. Y debe ser acompañada de un conjunto de medidas que «atrincheren» sus decisiones, incluso frente a sí misma. La fuerza de ese atrincheramiento dependerá, naturalmente, de la naturaleza de las cláusulas constitucionales que se protejan.

\section{VI}

Coda. Las consideraciones anteriores pretenden invitar a dibujar nuevamente las relaciones entre constitución y ley. La objeción democrática formulada como una reivindicación de competencias para el legislador cotidiano tiene que servir de aviso constante frente a las tentaciones de amparar bajo la rigidez constitucional aspectos de la vida colectiva que no merecen hurtarse a la voluntad de la mayoría. En ese sentido la objeción propugna una importante pleamar de la ley respecto de la constitución. Pero no excluye necesariamente que existan mecanismos rígidos de reforma siempre que tales mecanismos sean a su vez democráticos. Si las reformas de la constitución se articulan institucionalmente en forma de procedimientos democráticos de decisión, entonces la primacía de la constitución puede convivir perfectamente con el carácter democrático del ordenamiento. Rigidez constitucional y mayoritarismo no serían incompatibles. Hasta el punto de 
que el atrincheramiento constitucional de algunos derechos individuales y algunos procedimientos políticos sería precisamente la garantía protectora de la naturaleza democrática del sistema. Con ello la objeción democrática habría perdido gran parte de su fuerza y solo sería aplicable a supuestos de extremada intangibilidad constitucional o vetos para-mayoritarios.

¿Sucedería lo mismo con la clásica «objeción contramayoritaria» que se opone a que sea un pequeño número de jueces, de sabios, no elegidos democráticamente, los que decidan sobre el alcance de la constitución? No me atrevo a decir que sí, pero tiendo a pensar que si los mecanismos de reforma constitucional son conformes a los procedimientos de decisión democrática no podría decirse, o no podría decirse en sentido estricto, que doce jueces se han impuesto a una mayoría. Pero esto merecería una reflexión mucho más pausada.

\section{Referencias}

Ackerman, B. (1991) We The People. Vol. I: Foundations. Cambridge, Mass. Harvard University Press.

Ackerman, B \& Rosenkrantz, C. (1991) «Tres Concepciones de la Democracia Constitucional», en Fundamentos y alcance del Control Judicial de Constitucionalidad. Madrid. Centro de Estudios Constitucionales.

Alexander L. (1998) Constitutionalism. Philosophical Foundations. Cambridge University Press.

BAYón, J.C. (2000) «Derechos, Democracia y Constitución» en Discusiones n. 1 Derechos y Justicia Constitucional.

Bertz, Ch. R. (1989) Political Equality. An Essay in Democratic Theory. Princeton, New Jersey. Princeton University Press.

Bickel, A. (1986) The Least Dangerous Branch. The Supreme Court at the Bar of Politics. New Haven \& London. Yale University Press. (1 ${ }^{a}$ ed. 1962).

BRYCE, J. (1988) Constituciones rígidas y constituciones flexibles. Madrid. Centro de Estudios Constitucionales. (Ed. original 1884 y 1901)

Elster J. (1979) Ulysses and the Sirens. Cambridge. Cambridge University Press.

Elster J. (2000) Ulysses Unbound. Cambridge. Cambridge University Press.

Elster J. \& Slagstad R. (1988) Constitutionalism and Democracy. Cambridge. Cambdridge University Press.

Ferreres, V. (1997) Justicia Constitucional y Democracia. Madrid. Centro de Estudios Políticos y Constitucionales.

FERreres, V. (2000) «Una defensa de la rigidez constitucional» Doxa, 23, 2000

Fioravanti, M. (2001) Constitución. De la antigüedad a nuestros días. Madrid. Editorial Trotta (ed. orig. Bologna. Il Mulino. 1999).

GARZón VAldÉs, E.(1989) «Representación y Democracia» en Doxa, 6, 1989.

HoLmes, S. (1988) «Gag rules or the politics of omission», en Elster J. \& Slagstad R. (1988)

Holmes, S. (1995) Passions and Constraint. On the Theory of Liberal Democracy. Chicago and London. The University of Chicago Press. 
KAY R.S. (1998) «American Constitutionalism», en Alexander L. (1998).

Moreso J.J. (1997) La Indeterminación del Derecho y la Interpretación de la Constitución. Madrid. Centro de Estudios Constitucionales.

MoReso J.J. (2000) «Derechos y Justicia Procesal Imperfecta» en Discusiones n. 1. Derechos y Justicia Constitucional.

Mueller D. (1996) Constitutional Democracy. Oxford. Oxford University Press.

Nino C. (1993) «A Philosophical Reconstruction of Judicial Review», en Cardozo Law Review, vol. 14, January 1993, n. 3-4.

Pozzolo, S. (2001) Neocostituzionalismo e positivismo giuridico. Torino. G.Giapichelli editore.

Prieto Sanchís, L. (1997) Constitucionalismo y Positivismo. México. Fontamara.

Prieto SAnChís, L. (2000) «Tribunal Constitucional y Positivismo» Doxa, 23, 2000

Rawls J. (2001) Justice As Fairness: A Restatement. Edited by Erin Kelly. Cambridge, Massachusets. London, England. The Belknap Press of Harvard University Press.

Ruiz Miguel, A. (1989) «Problemas de ámbito de la democracia» en Doxa, 1989, n. 6

SunsteIn C. (1993) «Constitutionalism and Secession», en The University of Chicago Law Review 1991, n. 58, p. 633 y ss.

VARela, J. (1998) Textos básicos de la Historia Constitucional Comparada. Joaquín Varela Suances (ed.). Centro de Estudios Políticos y Constitucionales.

WALDRON, J. (1993) «A Right-Based Critique of Constitutional Rights» en Oxford Journal of Legal Studies. Vol 13, $\mathrm{n}^{\circ} 1$.

Waldron, J. (1999) Law and Disagreement. Oxford. Clarendon Press.

ZAGREBelsky G. (1995) El derecho dúctil. Ley, derechos, justicia. Madrid. Editorial Trotta. (traducción de Marina Gascón de la edición italiana Il Diritto Mitte). 